\title{
Application of Morphological Analysis Methodology in Architectural Design
}

\author{
A. Prokopska
}

The theory of system and design methodology as the sphere of concepts being objective mode can be applied to a more precise description, analysis and improvement of the methods of the real architectural design process.

Lull's art as the primary idea of morphological analysis, has been acknowledged as to an element corresponding with the specificity of architectural design. From the architect's point of view it is worth studying the rules and peculiarities of morphological analysis methodology.

In engineering design thus it may be possible to apply the methodology in architectural design.

Keywords: design, architecture, engineering, structure, morphology, analysis.

\section{Introduction}

Albert Einstein stated: "Science must start from facts and end with facts, irrespective of the theoretical structures that it uses to combine them" [1-4].

This statement is directly relevant to morphological analysis based on Lull's Art, as this method starts from facts and combines them in a mechanical way, thereby creating theoretical structures. According to this method, from among the theoretical structures formed in this way, only those are to be chosen, which will be in accordance with a pre-defined need.

Thus, the method assumes a decision-making role, the creative choice of a human-designer, which is an indispensable element of architectural design in a systemic approach. ${ }^{1}$

At present, the traditional understanding of architectural design $^{2}$ does not correspond fully with the assumed high level of complexity of technological and architectural design processes. The traditional understanding of design is also not consistent with the contemporary level of complexity of designed technical objects. In the creative method of morphological analysis [5-11], the study or design of fragments of reality, while treating these fragments as wholes composed of different parts, correspond to the contemporary level of complexity of designed technical objects.

The use of this method requires that a concept be introduced, which will make it possible to isolate the object of study or design. This concept is the system, and, in the case of architectural design, it is the architectural system [11].

The effect of the development of a design methodology which searches for general instructions of procedure and regularities that will refer to the broadest classes of processes of the design of technical objects, is, among others, the formation of the specific interdisciplinary conceptual means that accepts and facilitates a systemic approach to design.

Such a development of the methodology of design (Fig. 1) [9], means that the process of architectural design can be directly described and studied, without referring to the description of a designed object [12-14]. At present, not only design processes but also creation methods may be characterized, without the necessity to defined them directly, with the use of object descriptions [5]. According to our contemporary methodological knowledge, features formed in a design process are as fundamental as those which result

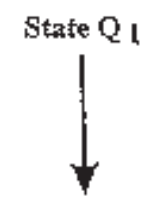

State $0_{2}$

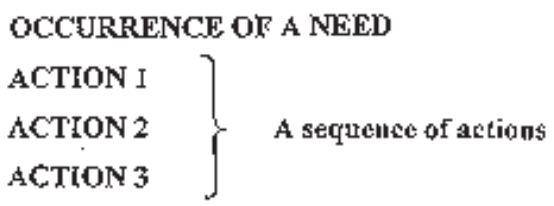

SATTSRACTION OF THE NEED

(AIM)
Fig. 1: Sequential basic actions in the process of satisfying needs [9]

from the function of the object, the material used for its production, and the production process.

These facts, on the background of knowledge resulting from the contemporary extensive development of the methodology of scientific design, involving the methods, procedures and techniques of design [6], form a reason for undertaking an attempt to study of the study of the morphological analysis methodology based on Lull's Art [5, 7], as that which can be applied not only in technology, but also in architectural design.

These remarks are the leading concepts of the presented considerations referring to the possibilities of applying morphological analysis or some parts of it in the real process of architectural design. The indispensable condition for these considerations is a systemic approach ${ }^{2}$ to the architectural design process and to design as an architectural system.

\section{Lull's art as a philosophy and a "Pre-concept" of the morphological analysis methodology}

Morphological analysis methodology has its "pre-concept" [7-8], which testifies not only to the richness but also to the continuity of human thought through the ages. Ramon Lull, (1235-1315), a monk from Majorca, later know as Raimundus Lullus, constructed a "logic machine" that performs automatic combinations of solutions. This consists in systematic combinations of a small number of notions.

These notions symbolize intervals on the orbits of concentrically rotating circles (App. 1) [8]. Ramon Lull called his method "Great Art", and later he reduced to nine the number of notions subject to automatic combination (App. 2) [5]. An 
example contained in the table, reprinted from a seventeen-century book, is a typical morphological interval (Fig. 2, 3, App. 3).

a)
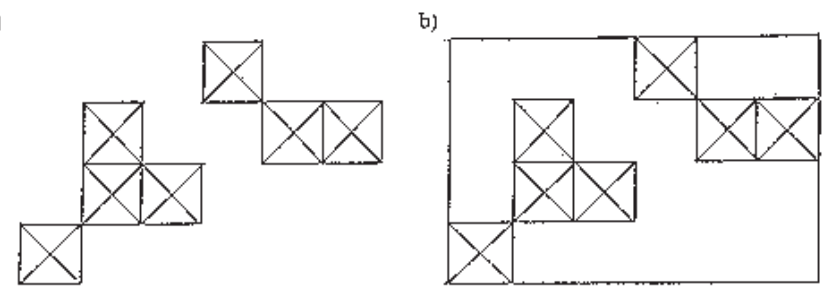

Fig. 2: a) Known solutions of the problem

b) Structuralized solutions having various new solutions of the problem inside their abstract structure.

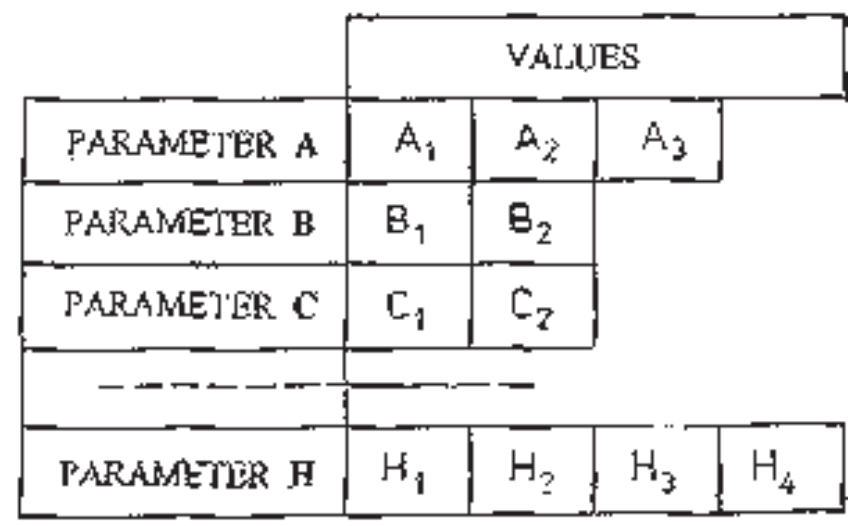

Fig. 3: A schematic drawing of a morphological interval [24]

Lull's Art, however, led to the danger that thought might be mechanized. Kant [5] expressed this danger as follows: "being young, I studied a little between philosophy and logics, ... but after studying them I am of the opinion that logics and syllogisms serve rather to explain things that are known, or even, as in Lull's Art, to speak without judgement about things of which we know nothing, and which we must learn".

Lull's methodology, as a basis of their philosophy, has been cultivated throughout the history by many thinkers, e.g., Giordano Bruno and G. W. Leibniz [5]. Leibniz wrote about it with appreciation in his Dissertatio de Arte Combinatoria. A. Kircher [5], a famous Jesuit (the inventor of the magic lantern, and thus the ancestor of the cinema) presented a clear example of morphological analysis (App. 3).

In Gulliver's Travels, Swift [5] criticizes Lull's Art by describing a device that sets letters in a random manner. This method enabled the most ignorant people to write books without the least help of genius or education. This criticism makes a clear distinction between what is morphological analysis and what is not.

In later centuries, Lull's Art gradually fell into oblivion, despite its potential values.

\section{Selected procedures of morphological analysis}

Morphological analysis was introduced by Fritz Zwicky [8-10], an astronomer ${ }^{3}$ who succesfully used this method, a pioneer of the construction of reaction engines.
Zwicky used the term "morphological analysis" to define a standard construction method that served for identifying all possible means enabling the attainmet of a specific functional capability. He was interested only in technical dimensions. He formulated a method for identifying, classifying and organizing the parameters influencing the construction of a physical device.

The processes of thinking known as morphological analysis or morphological exercise, go beyond Zwicky's morphological analysis, which is limited to the arrangement of technical factors.

The aim of contemporary thinking processes, whether they are called decomposition into semantic factors, morphological exercises, methods of morphological analysis, or simply "common-sense activity", is to search for more proper and meaningful factors through a continuation of the analysis of partial terms connected with complex terms, and complex terms covering partial terms [5, 8-9].

In morphological analysis, the value of solutions is connected with the value of the analysis, and the solutions must be consciously studied, and must also be used in future applications of this method in architectural design.

Gerardin [5] states that, in fact, "morphological analysis is a method of creation, and more precisely - a systematic help in creation". This does not eliminate creative work by a human beying, but stimulates and develops it, allowing the imagination to work on a larger number of ideas than would be possible with the classic approach.

Arthur D. Hall [14] defines morphological analysis as a generalization of the arrangement of properties, closely connecting them with morphological analysis itself. He regards the name as apt, since the word "morphology" refers to the science of structure and form (from Greek morphe - shape and logos - science). He claims that pondering on structure and form stimulates intuition, and helps in formulating the problems themselves.

The procedure of this method is presented by Hall as follows:

- start from the broadest possible formulation of the problem;

- make a list of the independent variables of the desired system;

- assign to each variable one of the dimensions of the morphological map;

- count the values that may be taken by each variable.

The total number of the problems will be equal to the product of the value numbers of each of the variables. In this method, the combination process grows in geometric progression, and tens of thousands of solutions are quickly obtained; thus it is necessary to distinguish clearly what is morphological analysis, and what is not.

The importance of this method does not consist exclusively in obtaining an ordered means of recording the combinations of the values of the features of an object in the morphological interval. Its essence lies in imposing a discipline and a systematic way of procedure on the designer, and, as a result, enabling successive choices to be made among many variant solutions [14-15].

To perceive an intrinsic order in a physically non-existing thing, and to settle the main features of thought out solution 
is the most difficult element of morphological procedure. It is also difficult to define the variants of the main features. Improper classification of the features of the thought-out solution may lead to an analysis of many contradictory or non-essential elements. Neglecting the essential values of features, on the other hand, may cause interesting concepts to be overlooked.

Gerardin [5] proposed that Zwicky's definition be replaced by another simple definition: "Morphological analysis is a method for systematic study of all the possible solutions of a given problem". According to this definition, a problem is considered in morphological analysis from the most general possible point of view, so that the greatest probability is obtained in examining all usable solutions of the problem.

Some solutions of the problem under consideration are however, always known (Fig. 2a, b). Thus in a procedure also consistent with morphological analysis, by starting from the analysis of a known or apparently right solution, the discovery of a new solution may be hoped for (Fig. 2b). Having undertaken the analysis of a problem by morphological analysis, its structure must then be defined and described in an abstract form, while limiting it, for example, to the form of a morphological matrix (Fig. 2b). By calculating all possible solutions, the set of possible solutions is investigated. A few of these solutions can be regarded as meeting the pre-determined requirements.

This method is particularly suitable for studying objects of a very high level of complexity, and for solving problems whose substance reduces to various combinations of a large number of elements. These elements, combined in various manners, form wholes of more and more new features, as happens in the process of architectural design.

The most important advantage of this method, as analysed from the viewpoint of its future application in architectural design, is that it leads, when the sets of main and particular features are properly determined, to the identification and investigation of all combinations of the real features of an object.

This morphological exercise depends on passing from one level of abstraction or population to others, in order to determine the essential change connected with a given problem.

At present, morphological analysis serves for the determination of a full set of combinations of the variants of the features of a defined class of technical objects, since it creates the possibility of making a choice.

It is important for architects that, thanks to these properties, this method makes it possible to obtain unconventional solutions, and, at the same time, to formulate complex problems in a general, comprehensive and clear manner.

Joining together the particular elements of an object under study in a combinatory manner, we can create (or generate) a huge number of types of systems. This task has a large, but always finite number of solutions.

In morphological analysis method, the examination of fragments of reality or their design, and regarding these fragments as a whole composed of various parts (e.g., architectural forms), corresponds with the modern level of complexity of design processes as intellectual processes, and the complexity of the design of technical objects, including architectural objects.

\section{Selected examples of the applications of morphological analysis}

In practical applications of this method in technology, success is attainable if a randomly selected set of solutions allows new ideas to be found. This is an attractive feature from the point of view of the specificity of an architect's design work.

Swager [15] describes an example of the use of morphological analysis in searching for real factors connected with the future of coatings in the package production industry. In this case, the analysis covered a number of conditions related to: transport, distribution, concept of marketing, changes in product manufacture technology, standards and government acts, changes in product forms, changes in demand for the products, and income per head.

During this morphological exercise which started with a description of the problem from the point of view of an evaluation of the importance and significance or lack of significance, an analysis was performed in relation to the usefulness and functions. In this analysis, each division or combination of the fragments of the description of the problem was investigated in terms of potential changes that could increase or decrease the future importance or requirements in relation to the described functions and usefulness.

Sielicki [6] presents in the following manner the course of a morphological procedure which is at the same time an analysis of an example of its application:

- for a given class of objects, a set of main features is defined: A,B,C, ...

- then, for each feature, its varieties or particular features are determined

$$
\begin{aligned}
& A_{1}, A_{2}, \ldots A_{k} \\
& B_{1}, B_{2}, \ldots B_{k} \\
& C_{1}, C_{2}, \ldots C_{k}
\end{aligned}
$$

This process can be continued to determine the subsequent varieties of the particular features.

- then all possible combinations of particular features or varieties of these features are determined. A graphical description can be used here, in the form of a table (Fig. 4), a tree of solutions (Fig. 5), a morphological matrix (Fig. 5) or a structural card (Fig. 6). In a situation when there are a considerable number of features and varieties of features, it is convenient to use computer procedures.

- the obtained set of variant solutions is subjected to reduction.

The remaining variants form the set of solutions searched for, and undergo further evaluation and reduction.

The set of solutions can be reduced, while searching for limitations that may exist as regards the values of various parameters. These limitations may reflect true impossibilities, physical, admissible values, also combinations, that seem to be unrealistic.

In order to study all solutions obtained through morphological analysis, the morphological interval must be defined (Fig. 3) in such a way that a number of different solutions be obtained, which correspond to a reasonable amount of time for studying them. In a morphological interval containing 

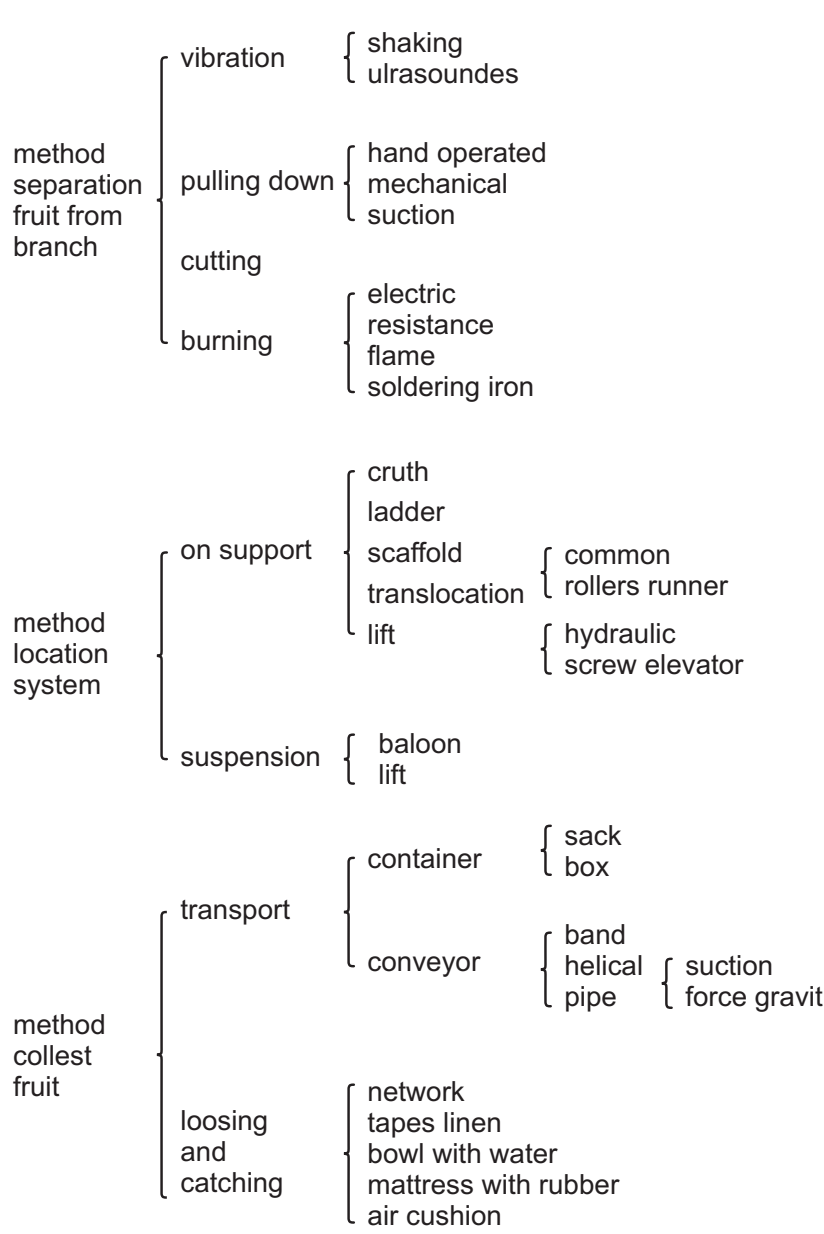

a)

Fig. 4: a), b) Table of the tree of solutions [9]

$A_{1}$ Means of transport

\begin{tabular}{|c|c|c|c|c|c|c|}
\hline & (S) & $(\mathrm{K})$ & $(\mathrm{M})$ & (R) & (J) & $(P)$ \\
\hline & SC & $\mathrm{KC}$ & $\mathrm{MC}$ & $\mathrm{RC}$ & JC & PC \\
\hline 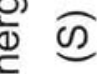 & SS & $\mathrm{KS}$ & MS & RS & JS & PS \\
\hline & SJ & KJ & MJ & RJ & $\mathrm{JJ}$ & PJ \\
\hline & SM & $\mathrm{KM}$ & MM & RM & JM & PM \\
\hline & SE & $\mathrm{KE}$ & ME & $\mathrm{RE}$ & JE & $\mathrm{PE}$ \\
\hline
\end{tabular}

Fig. 5: Two-dimensional morphological matrix [9]

seven parameters, each having three values, 2187 solutions are obtained. In the case of seven parameters, each having two values, only 128 solutions are obtained.

The example analysed above of the use of morphological analysis and a multitude of possible graphical descriptions of this method (Fig. 3, 4a, 4b, 5, 6, 7 and 8) describes and device for collecting apples, presented by Sielicki [6].

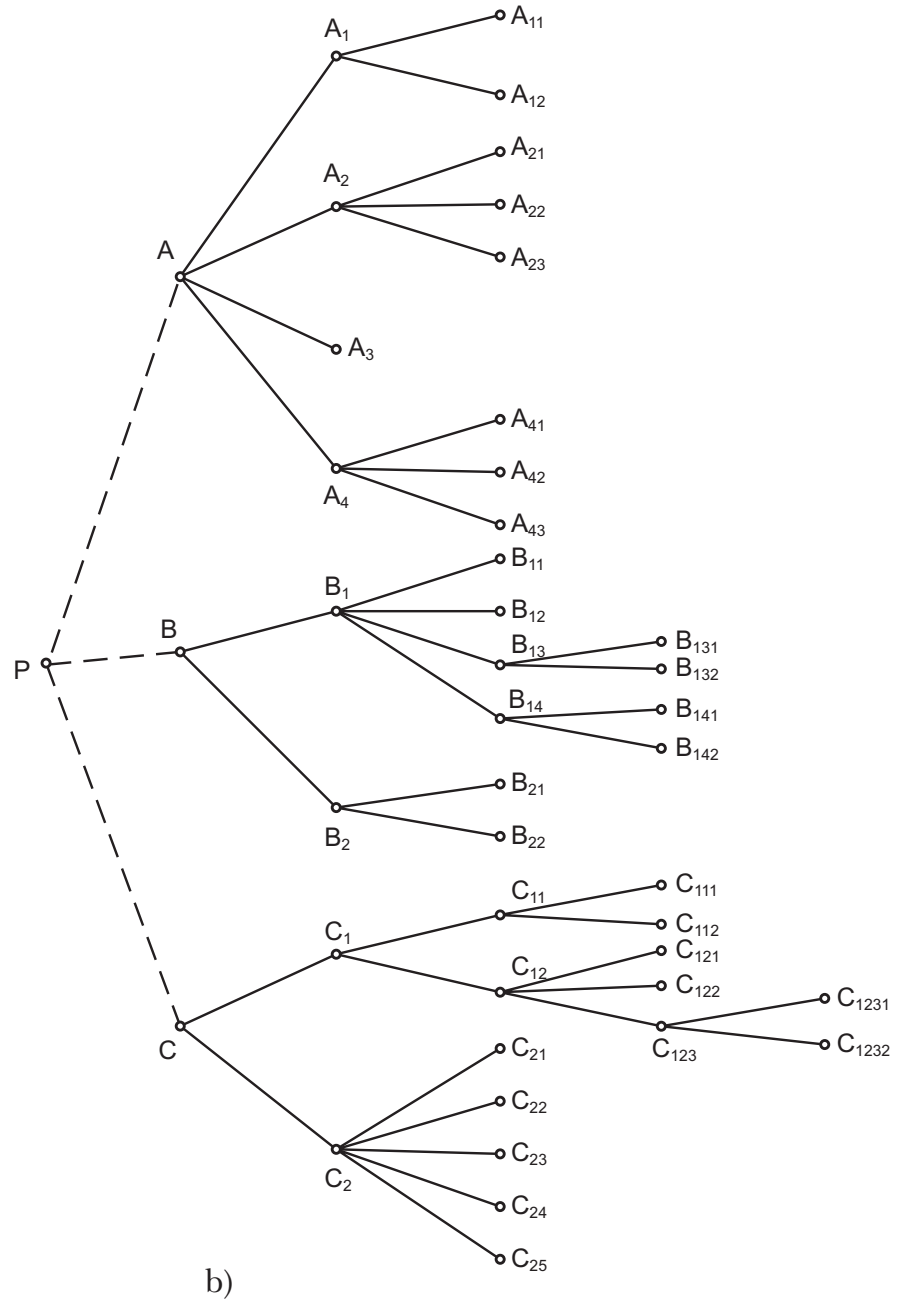

b)

The structure of description shown in Fig. 4a, b corresponds to the tree of solution variants. This structure can also be presented in the form of a so called structural card (Fig. 6) [4].

Another form of graphical representation is a morphological matrix (sometimes called a morphological box). The number of dimensions of this matrix is equal to the number of main features of the solution, and each of its elements corresponds to a defined combination of features (Fig. 5). Figure 7, on the other hand, gives an example of a two-dimensional matrix, which describes the main features of the same device for collecting apples.

The most convenient method of representation is a so called decision graph (Fig. 1) [6].

The number of possible paths in the graph corresponds to the number of possible variants of the solution.

In the decision graph shown, which is related to the process of architectural design, one design decision would be defined by one operational action, and would be depicted as passing from one graphical point to the second point. Thus, in the process of architectural design based on morphological analysis, an architectural object can be formed [6, 11, 13-14], in successive design steps taken as a result of evaluations made in accordance with the ideas, knowledge and skill of an architect. 


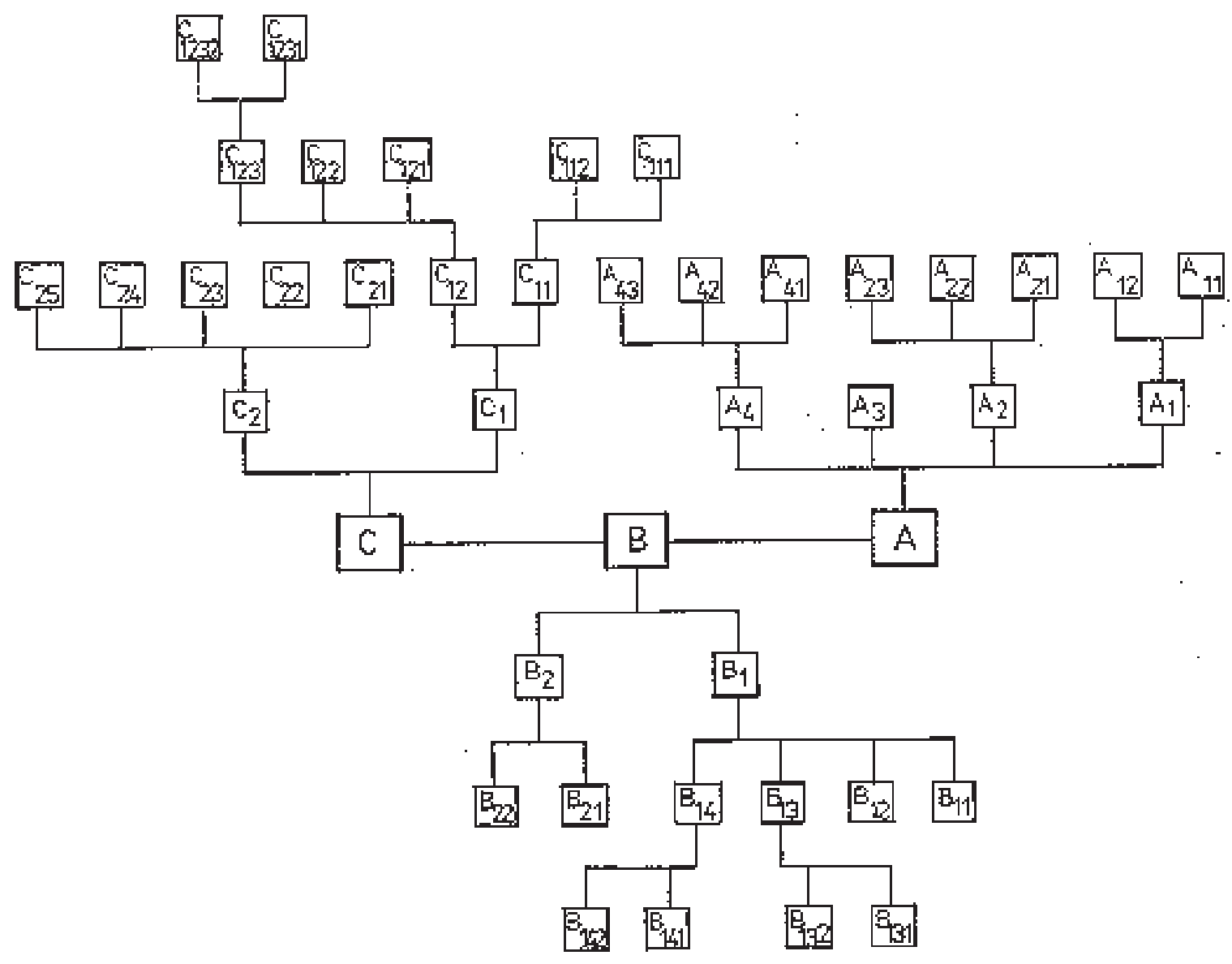

Fig. 6: A structural card [9]

\section{Discussion and Conclusions}

The modern development of the theories of system, proxeology, and design methodology, together with the development of concepts connected with these domains, has led to new possibilities of design and improvement in the real process of an architectural design system approach to design.

One of many consequences of the development of theories of system design methodology is an increase in the importance of new applications of various methods; this includes the method of morphological analysis known and applied in technology, which is based on Lull's Art.

In architectural design applications, this method, based on the arrangement of fragments into more or less complex wholes, requires a systemic approach.

A fundamental way of viewing morphological analysis methodology is to treat it consciously as a tool that increases the possibility of aggregating diversities in the process of architectural design.

From the point of view of an architect, morphological analysis has a particularly attractive feature that enables a designer to create freely and yet systematically many variants of the solution, according to a predefined need, and also according to his creative imagination, knowledge and skill.

The present development of design methodology is closely connected with design practice. The usefulness of future processes of architectural design, in which morphological analysis methodology will be applied, will result from the degree to which these processes will enable understanding, teaching and easier performance of architectural design.
Morphological analysis, as a mathematical method facilitates computer aid to the process of design, including architectural design.

The analysis undertaken here does not exhaust all possibilities of the use of a systemic approach to architectural design, and further study is recommended.

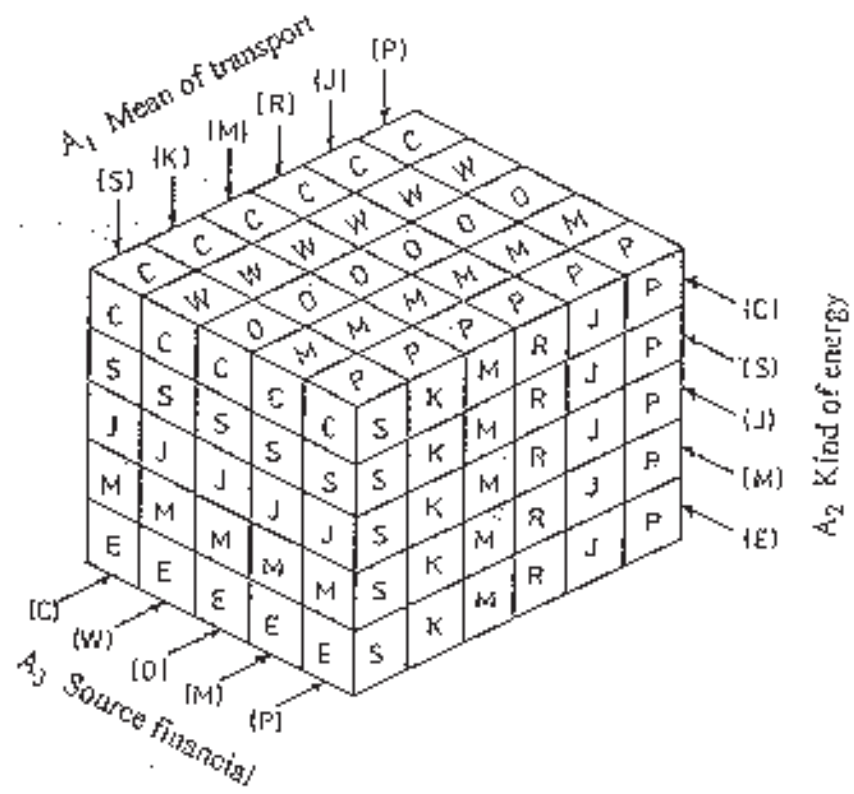

Fig. 7: Three-dimensional morphological matrix [9] 


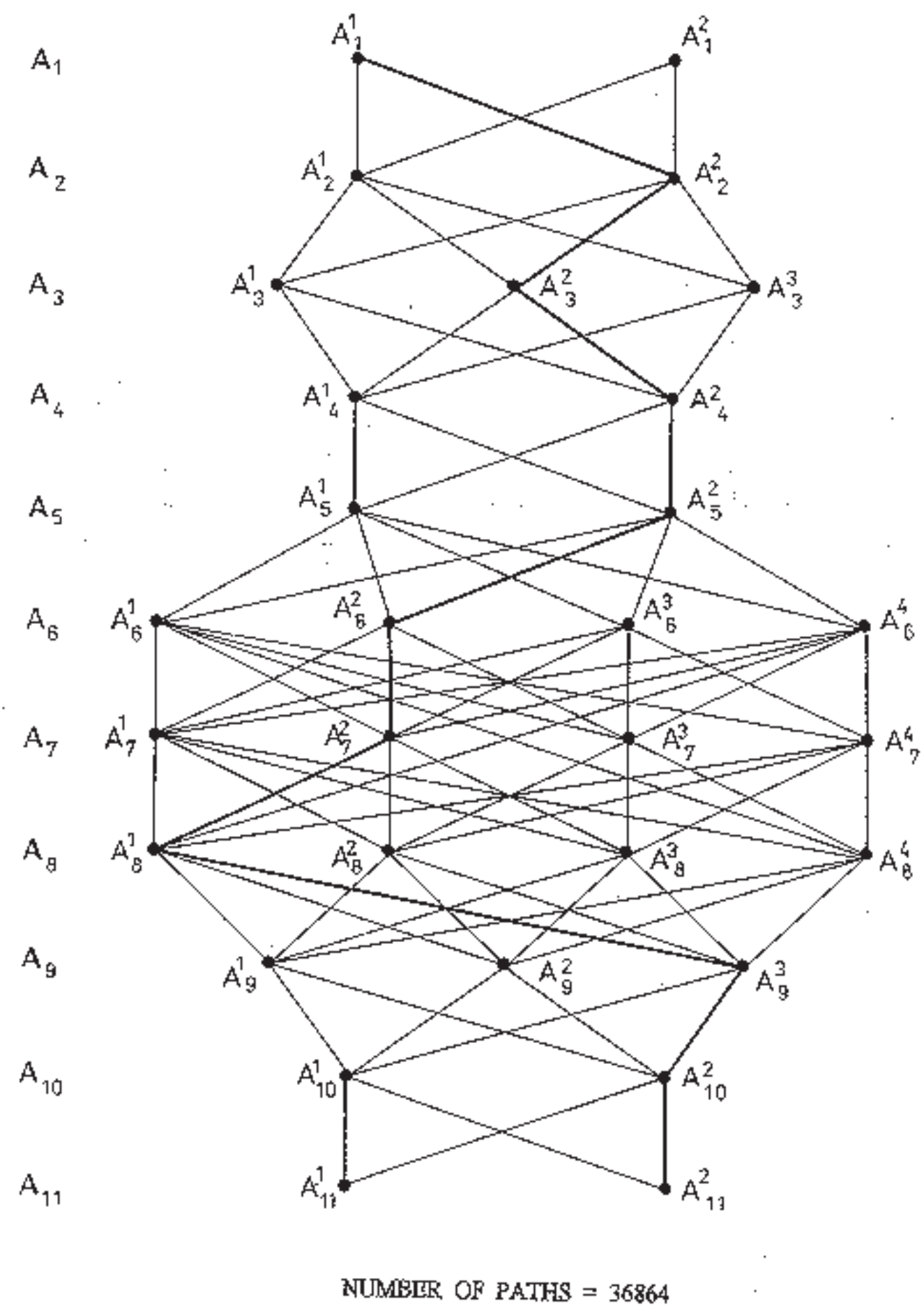

Fig. 8: A decision graph [9]

\section{References}

[1] Einstein, A.: The Common Language of Science. "Advancement of Science", II, 5/109, 1937

[2] Kuzniecov, B. G.: Einstein Albert. Evic, Warszawa-Moskwa 1959

[3] Einstein, A.: Historical and cultural perspectives. The Centennial Symposium in Jerusalem, Ed. by Gerald Holton, Yehuda Elkana, Princeton, Univ. Press, 1980

[4] Einstein, A.: Philosopher - Scientist. Ed. by Paul Arthur Sohilp Brothers Publ., Harper Toveh books, Science Library, New York, 1959, vol. 1, vol. 2
[5] Gerardin, L: Screenplays of future. Morphological Analysis the Method of Creation. in: A Guide to practical technological forecasting, Eds. Bright J. R. and Schoeman M. E. F., Prentice - Hall. Inc., Englewood Cliffs, New Jersey, USA, 1973, pp. 507-522

[6] Sielicki, A., Jeleniewski, T.: The Elements of the Methodology of Technical Design. WNT, Warszawa 1980 (in Polish)

[7] Swager, W. L.: Perspective trees - method of creative application of prognoses. In: A Guide to practical technological forecasting, Eds. Bright J. R. and Shoeman M. E. F., Prentice - Hall. Inc., Englewood Cliffs. 204-234, New Jersey, USA, 1973 


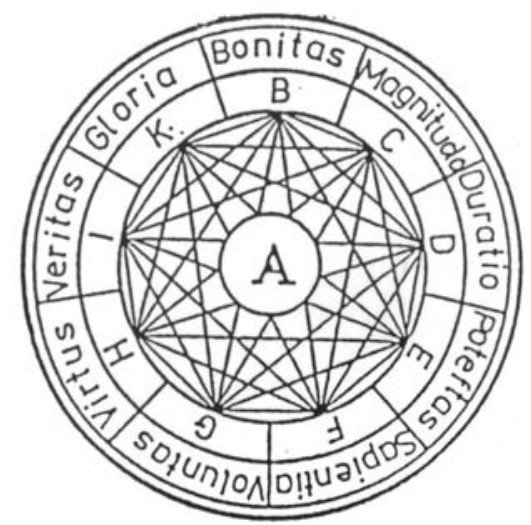

App. 1: Lull's Great Art [8]

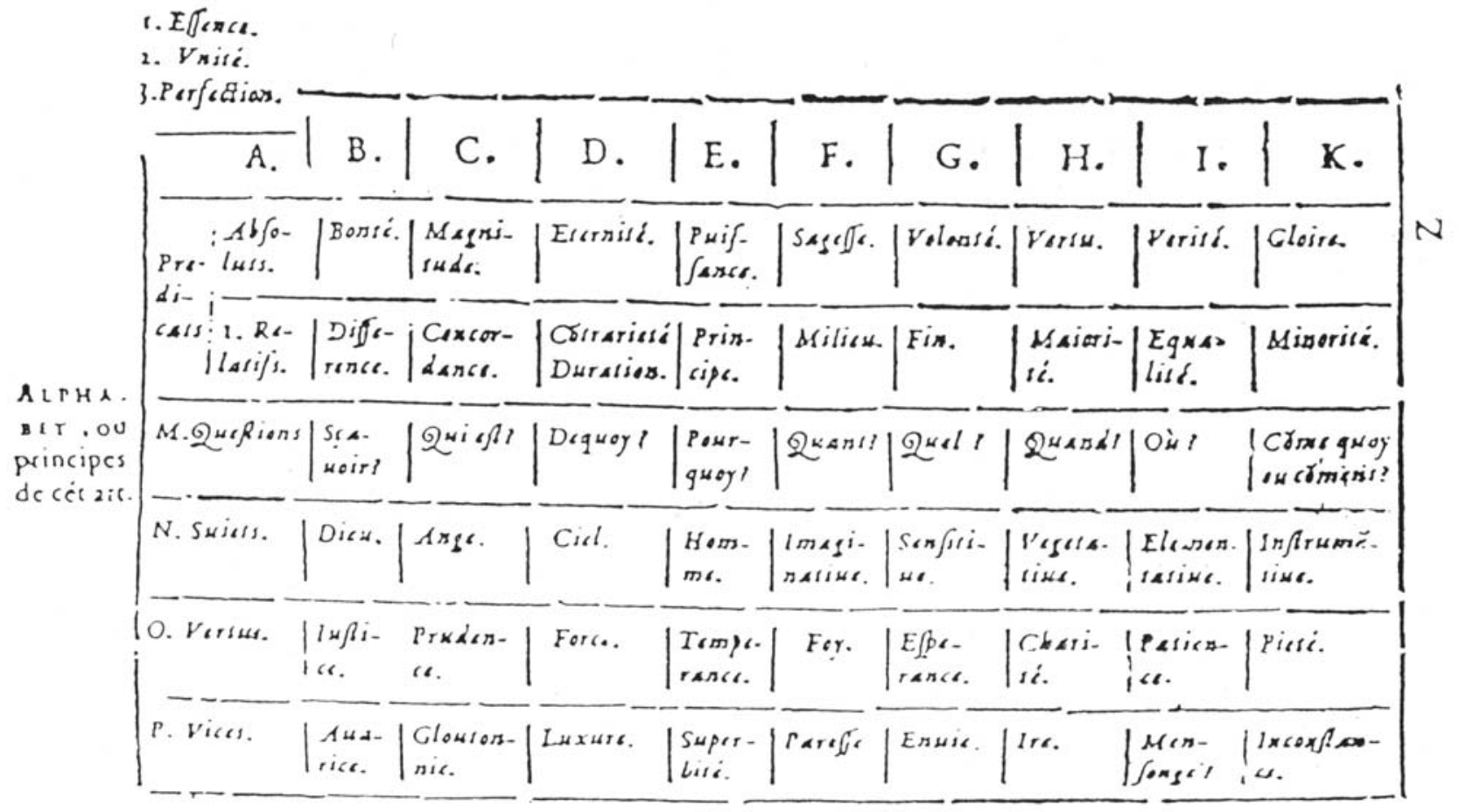

App. 2: Ramon Lull's Table [8]

[8] Zwicky, F.: The Morphological Method of Analysis and Construction. Courant, Anniversary Volume, Intersciences, Publ., New York 1948

[9] Zwicky, F.: Morphology and Nomenclature of Jet Engines. Aeron. Eng. Review, June 1947

[10] Zwicky, F.: Morphology of Propulsive Power Monographs on Morphological Research. No. 1. Society for Morphological Research, Pasadena, California 1962

[11] Prokopska, A.: Morphological analysis in architectural design. "Teka" Komisji Architektury i Urbanistyki
TXXVIII, Polish Academy of Science (PAN), Kraków, 1997 (pp. 185-195) (in Polish)

[12] Simon, H. A.: The Science of the artificial MIT Press. Cambridge, MA, USA 1969

[13] Simon, H. A.: The Style of Design. In: Designing and systems. Methodological problems, Vol. 3, Polish Academy of Science (PAN), Komitet Naukoznawstwa, 1981, pp. 97-115, Warsawa (in Polish)

[14] Simon, H. A.: Formulating, finding out and untie of problems in design. Design and Systems, Vol. XII, Zagadnienia 


$$
\text { JABU\{.1 COMBINATORJA. }
$$

Tex. I. JW.

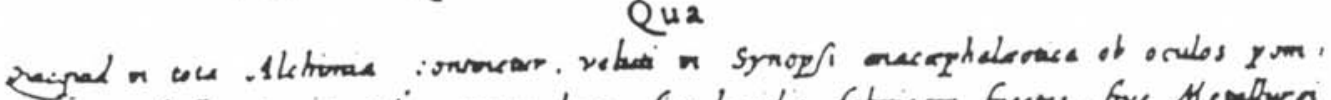

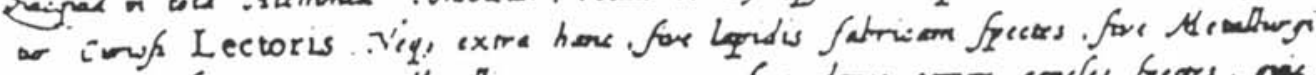

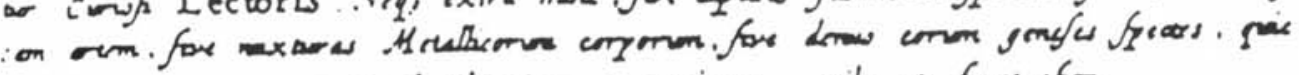

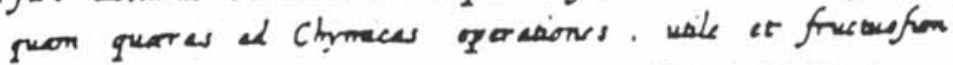

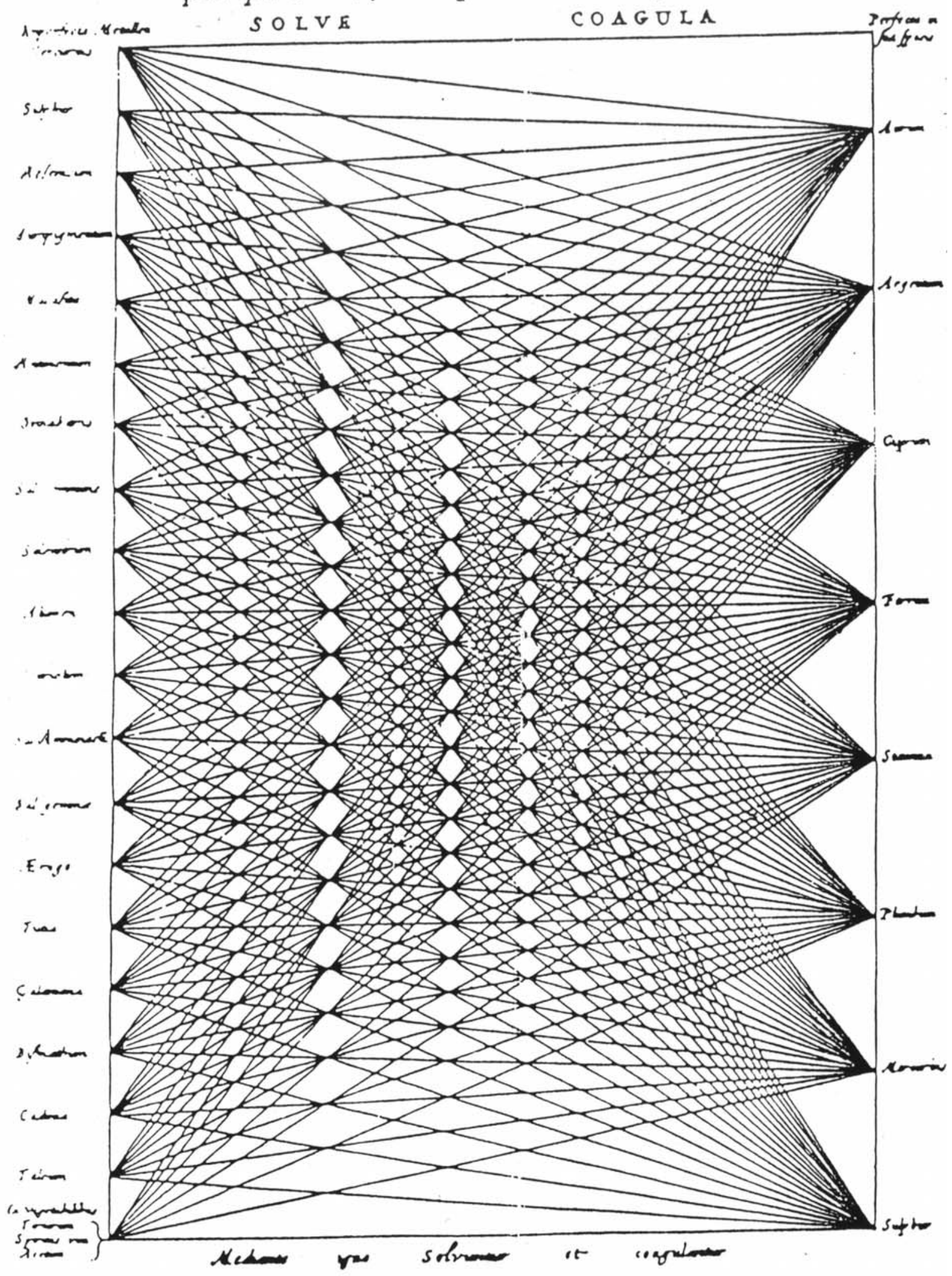

App. 3: A clear example of morphological analysis from 17th century, in [8] 
metodologiczne dyscyplin praktycznych, Wrocław-Warszawa-Kraków-Gdańsk-Łódź, Zakład Narodowy imienia Ossolinskich, Polish Academy of Sience (PAN), 1990 (in Polish)

[15] Swager, W. L.: Prespective trees - method of creative application of prognoses. In: A Guide to practical technological forecasting, Eds. Bright J. R. and Schoeman M. E. F., Prentice - Hall. Inc., Englewood Cliffs, New Jersey, USA, 1978, pp. 204-234
Prof. Aleksandra PROKOPSKA, D.Sc. arch Dept. of Town Planning and Architecture Faculty of Civil and Environmental Engineering Rzeszów University of Technology ul, Poznańska 2 35-084 RZESZÓW POLAND

\section{Endnotes}

1) The application of a systemic approach to architectural design may turn out to be difficult, as this approach requires precise knowledge which is not always available to the architect, since he acts in the sphere of intuition and professional know-how.

2) The so-called architect's design studio consist of know-how knowledge and know-how knowledge. The notion of an "architectural studio" is indispensable in architecture, and originates from the traditions of this profession, because architectural design originated from manufacture and has know-how in itself, i.e., knowledge which can be referred to as "I know, but I don't know how to say it". This knowledge can be described at least partly by means of the language of concepts in the theory of system and design methodology.

3) see also: Zwicky, F.: Morphological Astronomy. Springer Verlag. Berlin 1957 